\title{
Numerical Simulation of Pintle Thrust Adjustable Solid Rocket Motor
}

\author{
Guancheng $\mathrm{Pan}^{\mathrm{a}}$, Xiong $\mathrm{Chen}^{\mathrm{b}}$ and Xiaobing $\mathrm{Ye}^{\mathrm{c}}$ \\ Nanjing University of Science and Technology, Nanjing, China, 210094

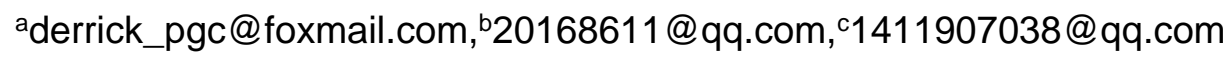

Keywords: Thrust adjustable, solid rocket motor, Nozzle efficiency.

\begin{abstract}
Numerical simulation of the flow field inside pintle controlled solid rocket motor was performed. The effects to nozzle performance with different pintle contour shapes and pintle position were investigated. The results showed that the influence of these factors to pintle nozzle efficiency was evident. The conclusion would be helpful for design experiment and application of pintle controlled solid rocket motor.
\end{abstract}

\section{Introduction}

With the development of missile defense technology, the maneuverability and penetration capability of missile is one of the issues that all countries pay close attention to. In order to improve the maneuverability and penetration capability of missile, the missile is usually equipped with many parameters, such as attack angle and velocity. The variable thrust technique of solid rocket has solved this problem to a great extent. Among them, the gas flow regulation is to control the thrust of the missile by changing the gas flow of the engine, so as to complete the orbit control of the missile. At present, the most effective way to control the gas flow is to adjust the throat area of the engine nozzle to control the working pressure of the engine, so as to achieve the engine gas flow control, to achieve the purpose of thrust adjustment. The variable thrust technology of solid rocket has been studied abroad, and the flight test has been carried out. A wide range of theoretical analysis and preliminary experimental studies have been carried out in china ${ }^{[1]}$.

In this paper, the theoretical analysis of variable thrust solid rocket motor was carried out. The relationship between the of the pintle tip contour, the position of the pintle and the flow loss and the efficiency of the nozzle were studied by means of numerical simulation. It has important reference value for the design of pintle tip contour and the study on matching of pintle and nozzle ${ }^{[2]}$.

\section{Mathematical Model}

\subsection{Basic Assumptions}

1. The eccentricity of the pintle is not taken into account. Using a 2D axisymmetric model.

2. The medium is a single ideal gas

3. Wall insulation, no heat exchange

4. Regardless of radiation, gravity, physical effects

\subsection{Control Equation}

The compressible flow of the conservation N-S equation can be written in the Cartesian coordinate system as follows:

$$
\frac{\partial \mathrm{U}}{\partial \mathrm{t}}+\frac{\partial \mathrm{E}}{\partial \mathrm{x}}+\frac{\partial \mathrm{F}}{\partial \mathrm{y}}=\frac{\partial \mathrm{E}_{\mathrm{v}}}{\partial \mathrm{x}}+\frac{\partial \mathrm{F}_{\mathrm{v}}}{\partial \mathrm{y}}
$$

Where $U$ is conservation type variable term. $E$ and $F$ are conservation type flux term. $E_{v}$ and $F_{v}$ are viscous term. The convection term in the calculation is separated by the second order windward. The viscous term is separated by the central difference format. The time term are separated by the first order of the difference format. The k-epsilon RNG turbulence model was used to calculate turbulence stress. The wall surface adopts the non-equilibrium function.

\subsection{Boundary Conditions}

Inlet condition: Assuming the inlet is uniform gas, given total moderate mass flow rate.

The pressure of the combustion chamber was obtained by the following: 


$$
\mathrm{P}_{\mathrm{c}}=\left(\mathrm{a} \rho \mathrm{c}^{*} \frac{\mathrm{A}_{\mathrm{b}}}{\mathrm{A}_{\mathrm{t}}}\right) \frac{1}{(1-\mathrm{n})}
$$

Mass flow rate was obtained by the following:

$$
\dot{\mathrm{m}}=\mathrm{aP}_{\mathrm{c}}^{\mathrm{n}} \rho_{\mathrm{p}} \mathrm{A}_{\mathrm{b}}
$$

Where $A_{b}$ is surface area of propellant, $\rho_{b}$ is density of propellant. $P_{c}$ is combustion chamber pressure, $\mathrm{n}$ is pressure index, $\mathrm{a}$ is burning rate coefficient, $\mathrm{c}^{*}$ is propellant characteristics speed.

Outlet condition: supersonic outlet.The parameters were extrapolated.

\section{Numerical Examples and Analysis of Results}

\subsection{Effect of the Pintle Tip Contour}

In order to study the effect of different pintle tip contours to the nozzle flow field, five different types of pintle were designed: configuration 1 large arc type, configuration 2 small arc type, configuration 3 blunt type, configuration 4 small angle triangular cone type, configuration 5 large angle triangular cone type. The five pintles were the same size as figure 1 , only changing the tip contour. The equivalent throat area and expansion ratio of the five nozzles with pintle were the same as those of the standard nozzle. The standard nozzle used for the calculation is shown in Figure 2 (unit $\mathrm{mm}$ ). The ratio of specific heats of propellant is 1.274, burning temperature is $2889 \mathrm{~K}$. Therefore, the theoretical specific impulse of this expansion ratio is $2212 \mathrm{~m} / \mathrm{s}$.

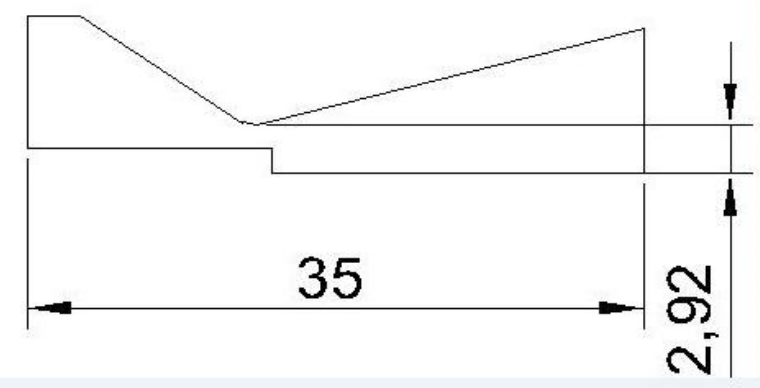

Fig. 1 Structural dimension of nozzle with pintle

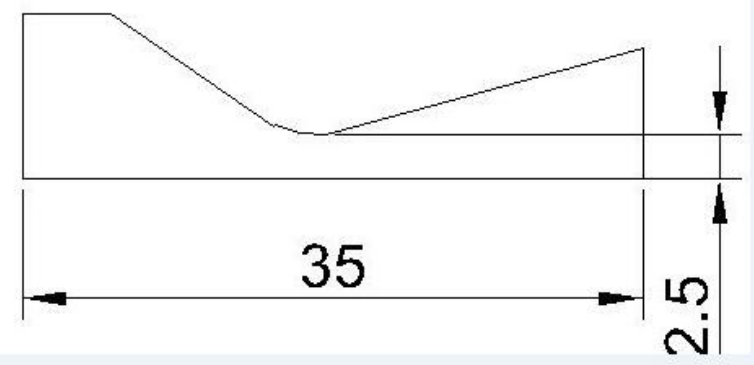

Fig. 2 Structural dimensions of standard nozzle

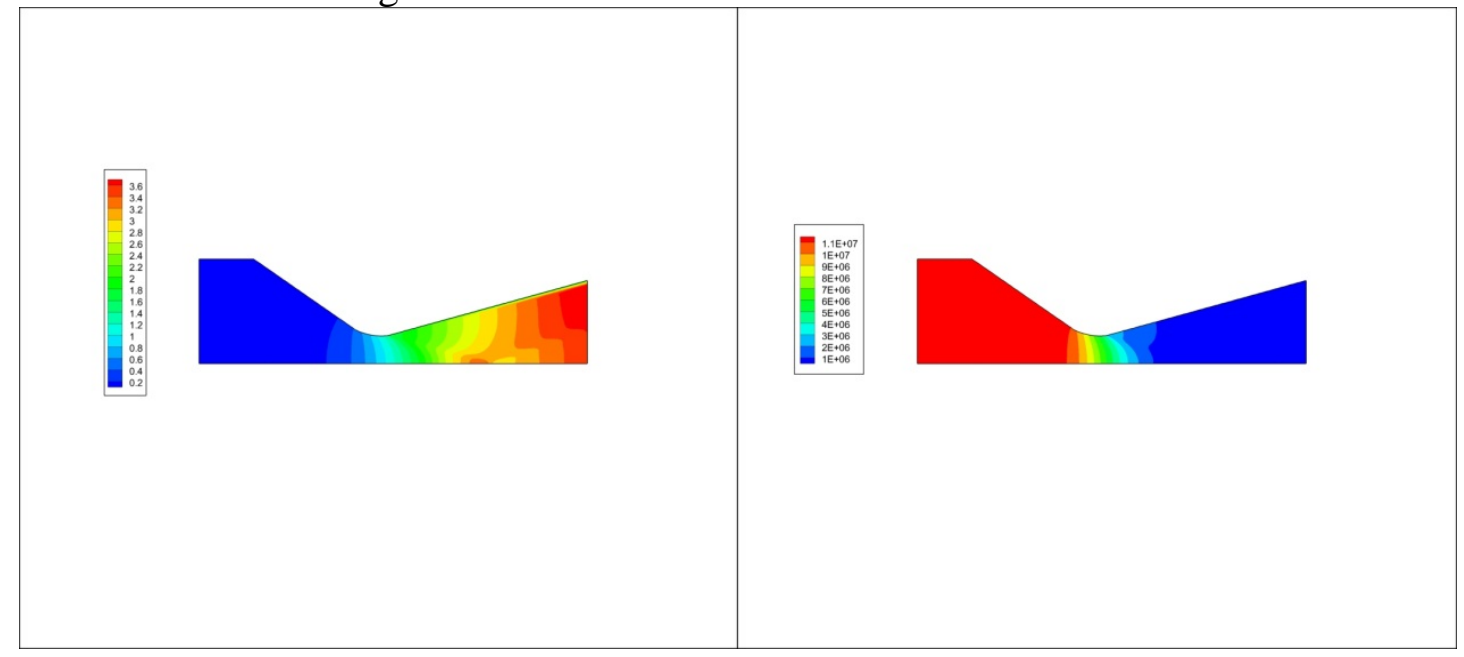

(a) 


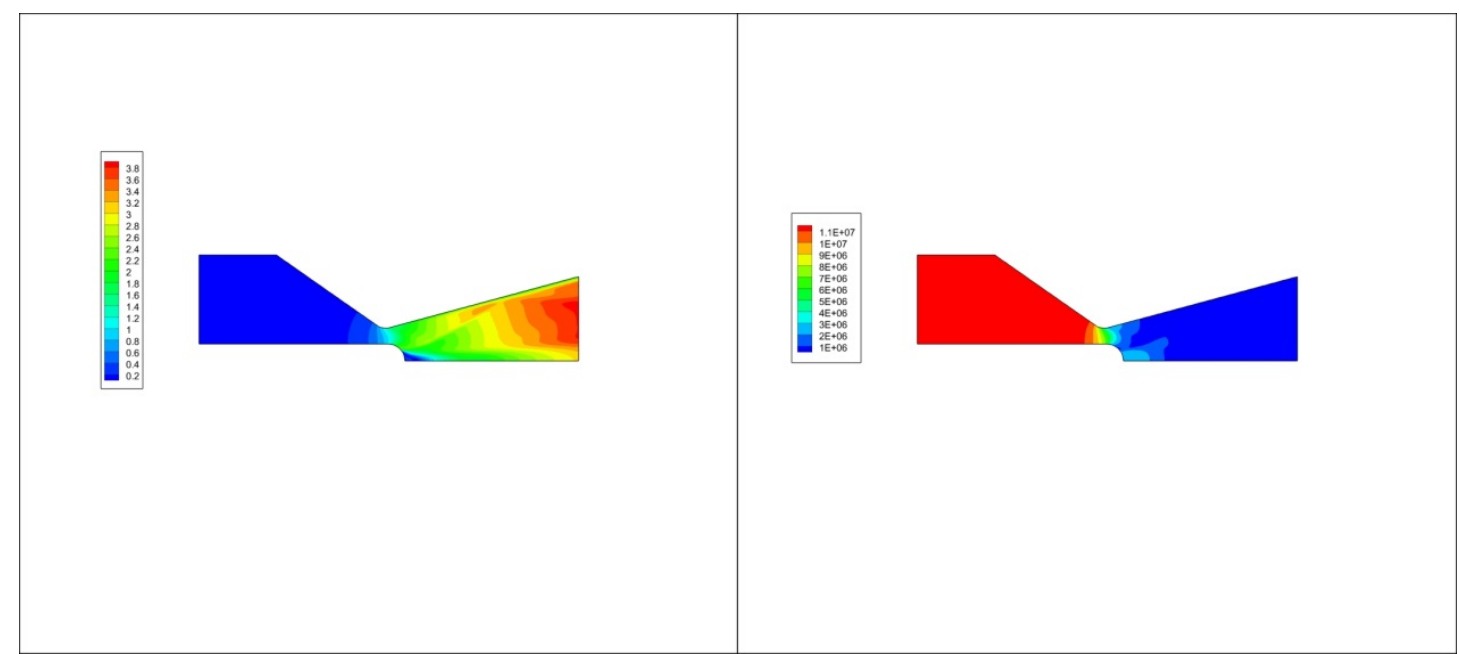

(b)

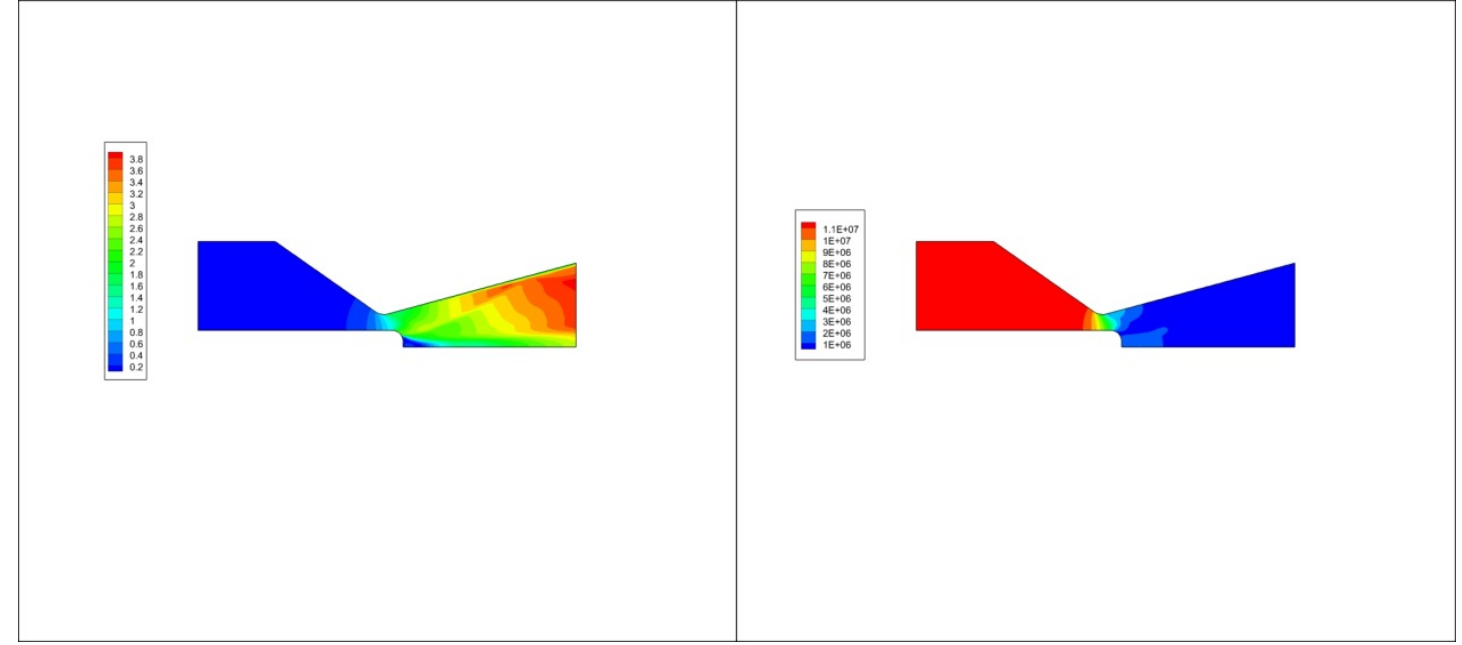

(c)

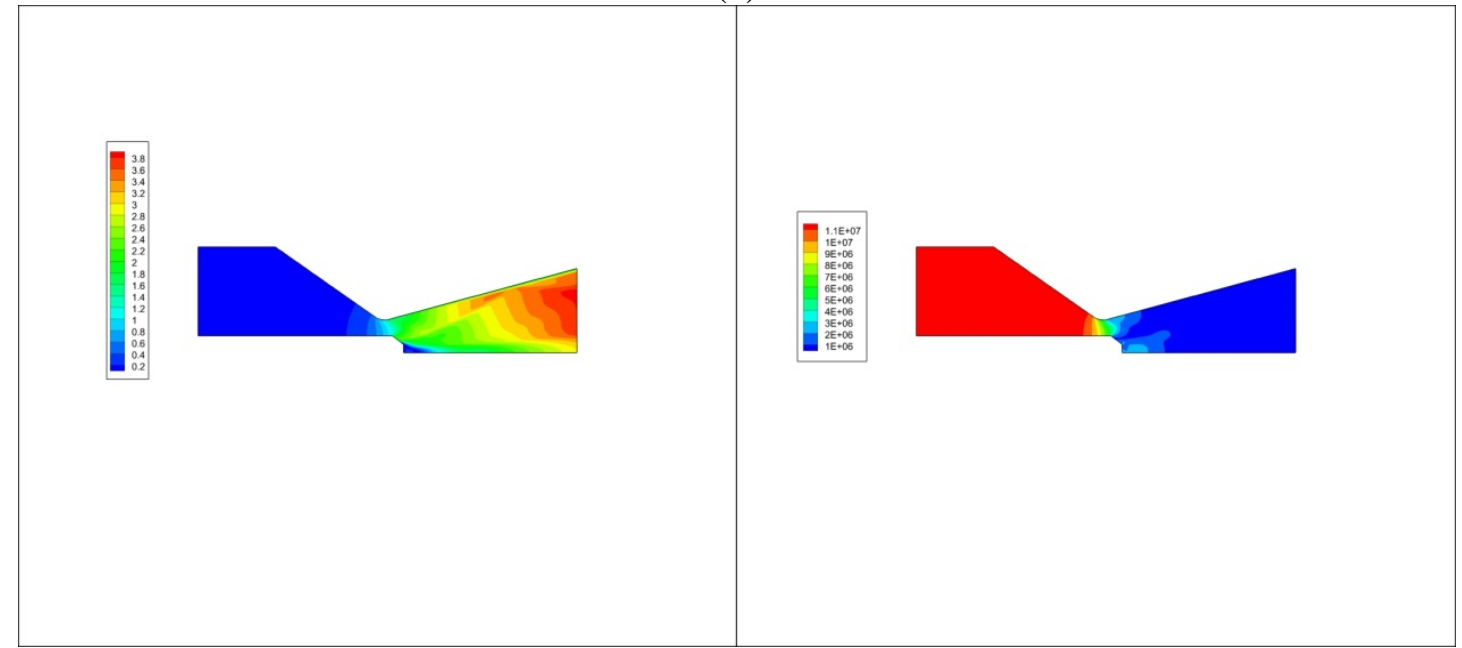

(d) 


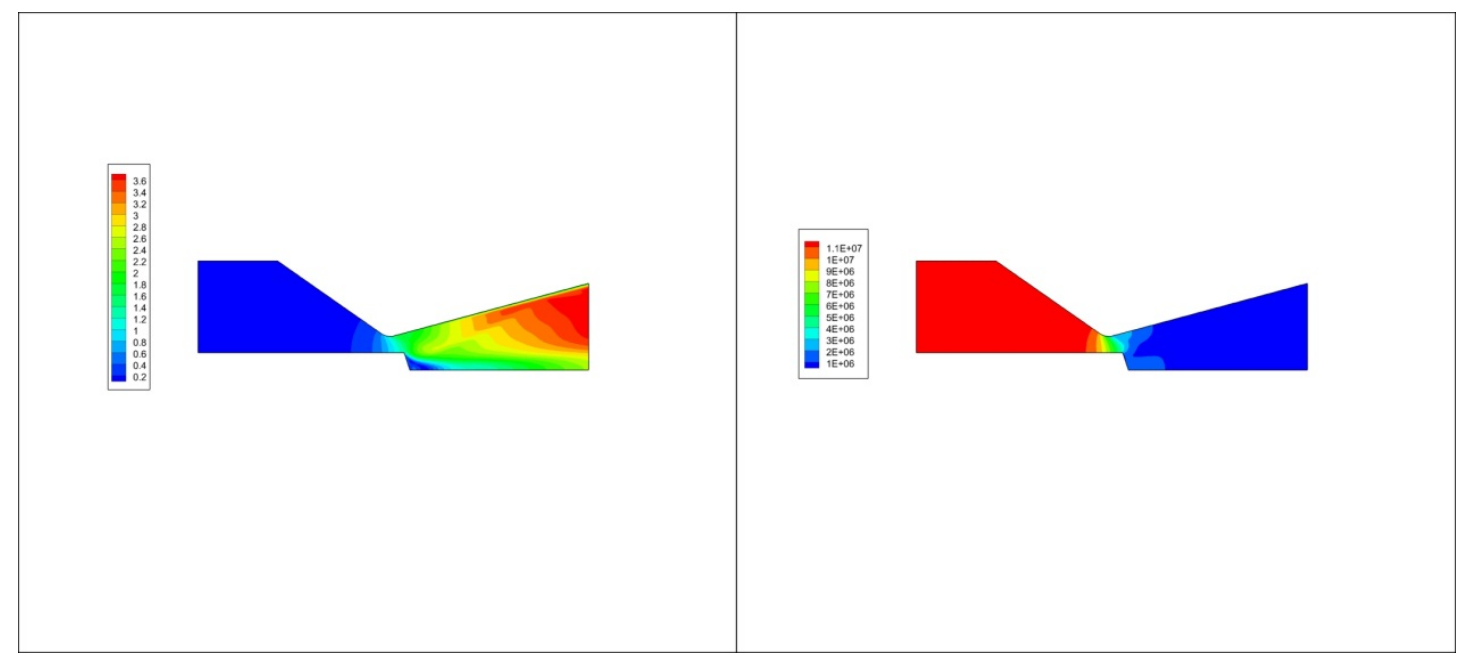

(e)

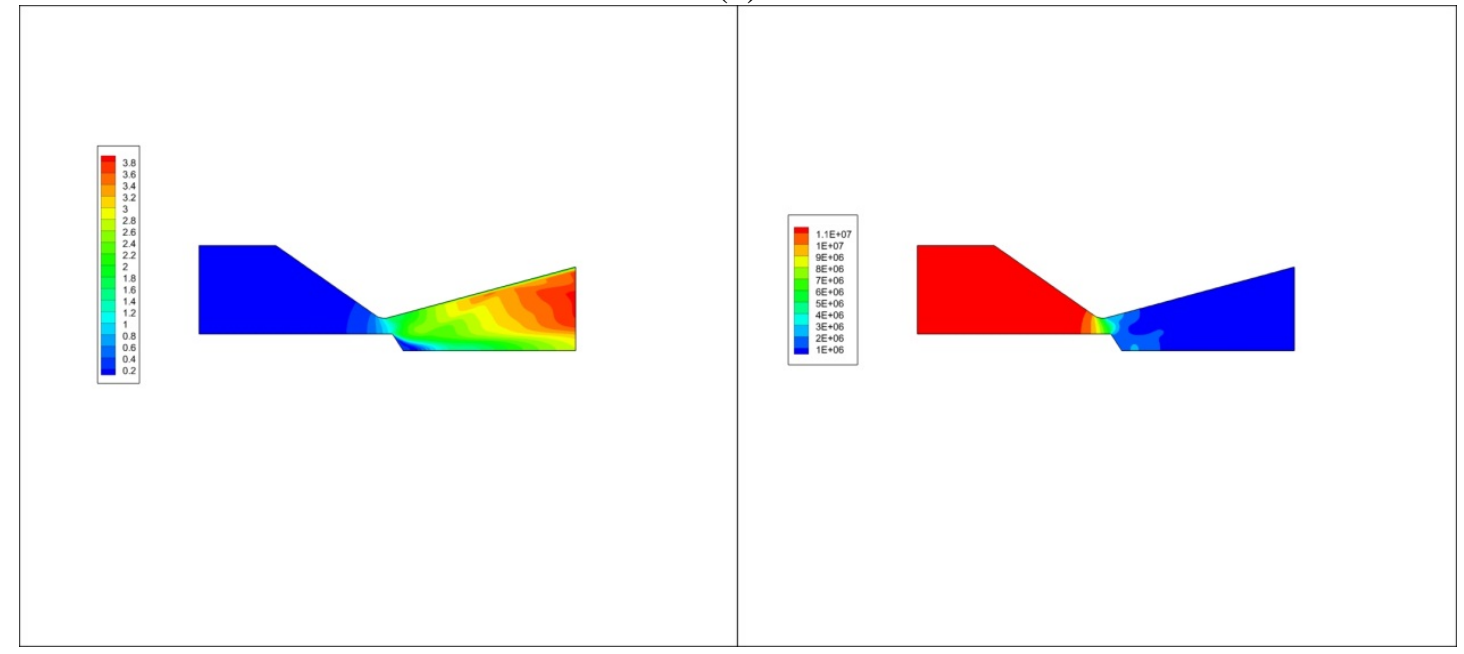

(f)

Fig. 3 Comparison of Mach contours and pressure contours with different pintle tip contour.

It can be seen from figure 3: Compared with the standard nozzle, the pressure contours of the nozzle with the pintle changes. The pintle of five configurations produced shock wave from the top of the pintle, after the gas passed through the shock wave, a subsonic area with a higher static pressure was formed at the top of the pintle. The axial force produced by this pressure acting on the pintle has a great influence on the movement of the pintle. And the high requirement for the strength of the pintle requires consideration in design. At the same time, due to the impact of shock waves, the high Mach number region at the nozzle outlet became smaller, and the outlet pressure was lower, which resulted in a decrease in specific impulse efficiency. 


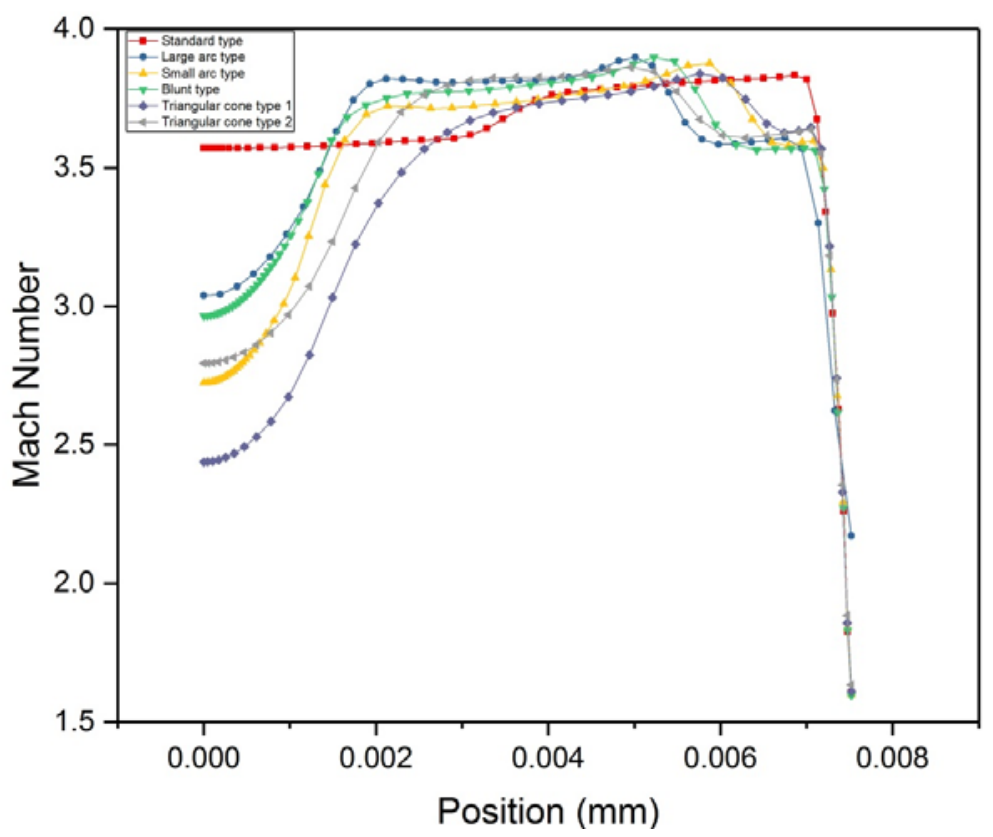

Fig. 4 Comparison of Mach number at outlet in nozzle with different pintle tip contour

It can be seen from figure 4: the standard nozzle had more uniform distribution of Mach number. And the Mach number of the nozzle outlet with the pintle changed greatly near the symmetry axis. Between 2mm and 5mm, the Mach number was higher and stable. The Mach number near the wall drops again. The reason for this fluctuation was caused by the shock wave at the top of the pintle. After passing through the shock wave, the velocity of the gas changed in different degrees, leading to uneven distribution of the Mach number of the outlet. It can be seen that due to the influence of the pintle, the Mach number of their outlet changes greatly than the standard nozzle, so the specific impulse was lower than the standard nozzle.

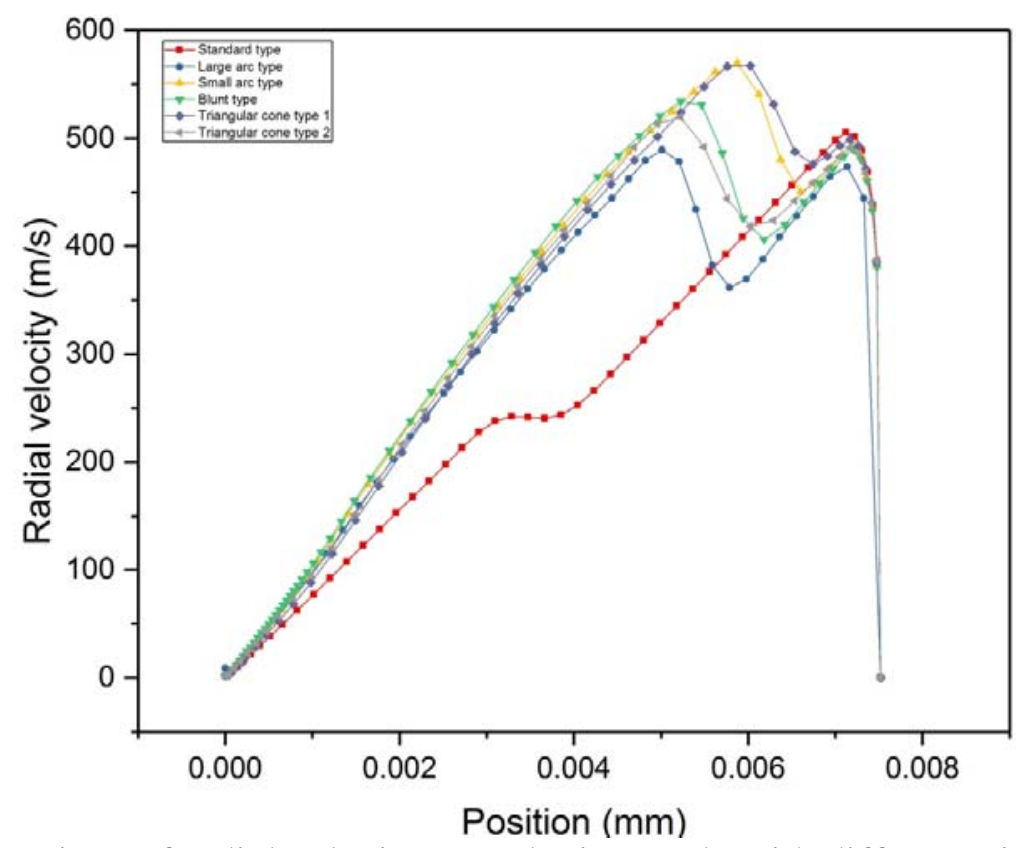

Fig. 5 comparison of radial velocity at outlet in nozzle with different pintle contour

In addition to Mach number, the velocity component is also an important factor affecting the performance of the nozzle. Ideally designed nozzles should have no radial speed in the outlet. In fact all the nozzles with the pintle are significantly different from the ideal nozzle. As shown in the figure: The radial velocity of the nozzle outlet with the pintle was much higher than the standard nozzle. Because only the axial velocity is comparable to the specific impulse, the standard nozzle has the highest specific impulse efficiency. 
Table 1. Comparison of nozzle efficiency of different configuration pintle

\begin{tabular}{cccc}
\hline Types & Thrust F/N & Specific impulse & Efficiency \\
\hline Standard type & 365.52 & 2097.19 & $94.81 \%$ \\
Large arc type & 360.92 & 2061.41 & $93.19 \%$ \\
Small arc type & 361.47 & 2063.72 & $93.30 \%$ \\
Blunt type & 361.51 & 2063.56 & $93.29 \%$ \\
Triangular cone type 1 & 354.82 & 2057.95 & $93.04 \%$ \\
Triangular cone type 2 & 355.57 & 2061.49 & $93.20 \%$ \\
\hline
\end{tabular}

It can be seen that the small arc pintle has the highest specific impulse efficiency.

\subsection{Effect of the Pintle Position}

The thrust adjustment of the variable gas flow type solid rocket engine mainly relies on the movement of the pintle to change the throat area of the nozzle. When the pintle is drawn out, the throat area is the biggest, and the combustion chamber pressure is lowest. When the pintle moves towards the throat, the pressure in the combustion chamber increases with the change of the position of the pintle, and the flow field in the nozzle will change accordingly.

The small arc pintle with higher specific impulse efficiency was used to calculate the flow field of three different positions to analyze the influence of the position of the pintle to the flow field of the nozzle. Position 1, position 2 and position 3 correspond to the smallest, middle, and largest throat areas, respectively. The calculation results are shown in Table 2.

Table 2. Comparison of nozzle efficiency at different pintle positions

\begin{tabular}{cccc}
\hline & position1 & position2 & position3 \\
\hline Nozzle expansion ratio & 3.00 & 2.81 & 2.65 \\
Theoretical specific impulse (m/s) & 2212.00 & 2183.53 & 2156.83 \\
Actual specific impulse (m/s) & 2063.72 & 2039.73 & 2023.84 \\
Specific impulse efficiency & $93.30 \%$ & $93.41 \%$ & $93.83 \%$ \\
Thrust (N) & 361.47 & 332.91 & 304.96 \\
\hline
\end{tabular}

It can be seen that as the pintle was drawn out from the minimum throat area, the specific impulse of the nozzle showed a downward trend. From position 1 to position 2, the actual specific impulse decreases greatly which almost as same as the theoretical specific impulse. But from the position 2 to the position 3, the actual specific impulse decreases slightly, and it was different from the theoretical decline. Note that other losses occurred at position 3. Figure 5 (a), (b) shows that the reason for this is the positions of shock waves were different after wall reflection at position 2 and position 3 . Therefore, the efficiency of the nozzle varies with the position of the pintle.

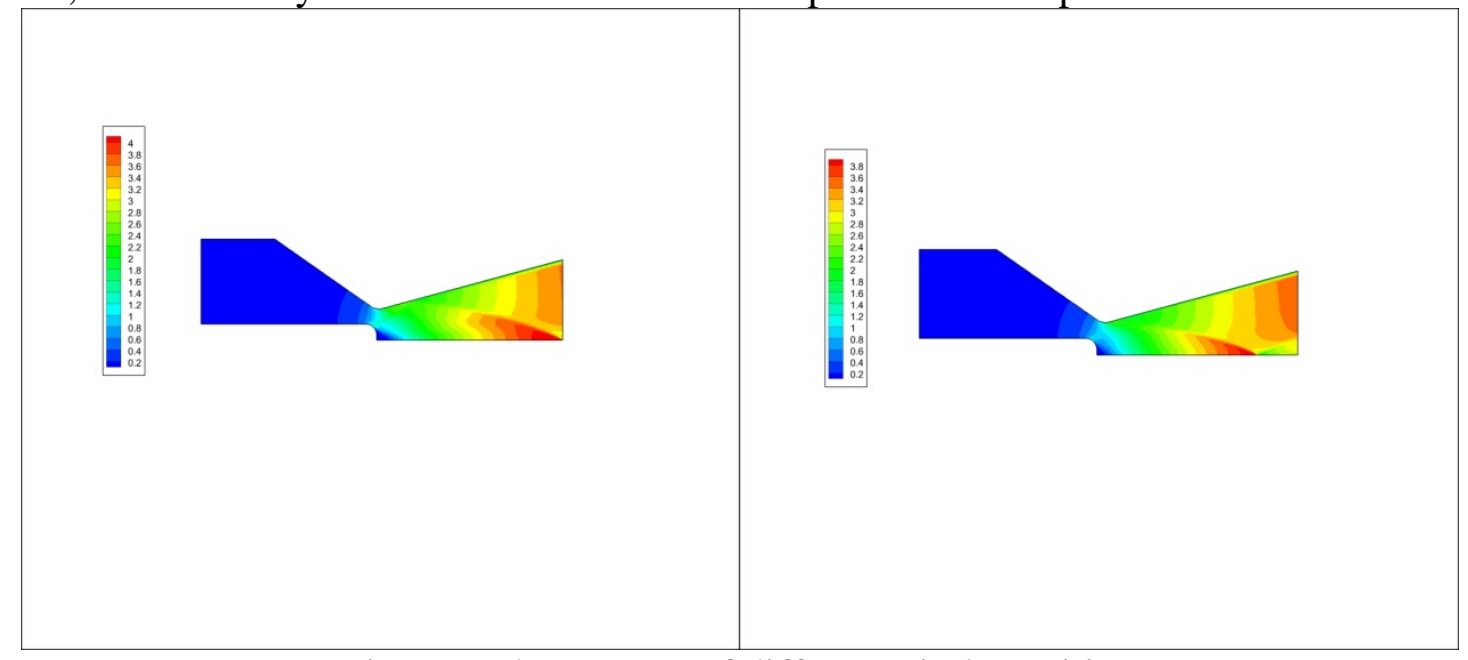

Fig.6 Mach contours of different pintle position

\section{Conclusion}

(1) Five kinds of the pintle tip contours were studied. The small arc pintle was the most efficient. It showed that the small arc pintle was the closest to the optimized surface of the engine. Compared 
with various pintle tip contours, the pintle tip configuration should be more circular and without obvious angular configuration to produce less disturbance to the nozzle outlet flow.

(2) The effect of the pintle position showed that in the process of pintle moving from the minimum throat area to the maximum throat area, the length and position of the shock wave changed. It resulted in the increase of specific impulse loss, which caused the nozzle efficiency to change with the position of the same pintle tip contour. Therefore, the position of the pintle must be pointed out when optimizing the pintle tip contour.

\section{References}

[1]. Jin-Lan Tang, Bo Hu, Jin-Xian Li, the Analysis of Non-coaxial Pintle Control Nozzle Thrust Performance and Influence Factor. Journal of Projectiles, Rockets and Guidance, 2013, 33(4):123-126.

[2]. Juan Li, Jiang Li, Analysis for Nozzle Performance of Pintle Controllable Thrust Solid Rocket Motor. Journal of Projectiles, Rockets and Guidance, 2007, 27(3):154-157. 